\title{
Financial watchdog to probe fines that hit vulnerable NHS patients
}

The growing problem of patients being affected by fines for wrongly claiming free NHS dental care is to be investigated by the financial watchdog the National Audit Office (NAO). ${ }^{1}$

The NAO has announced an investigation starting in the Spring into healthcare penalty charge notices (PCNs) that are given to patients for misclaiming free NHS dental care.

The BDA welcomed the investigation saying the 'aggressive' policy, supported by government campaigns such as \#DontRuntheRisk, had seen more than 400,000 often high-need patients a year receiving $£ 100$ fines simply for ticking the wrong box on claim forms, when many of these patients were on low incomes, older patients or were people with learning difficulties.

For its investigation, the NAO will set out the scale of activity in this area including:

- The number of penalty charges issued

- The outcomes of these

- The revenue generated for the NHS

- The cost of running the collection services.

It will also set out the entitlement to exemptions and the steps the NHS Business Services Authority, as well as the Department of Health and Social Care and NHS England, take to improve the efficiency of the system.

The BDA said the latest NHS dental statistics had revealed a collapse in attendance among patients who were exempt from paying NHS dental charges, and it had deep concerns that the government had cultivated a hostile environment to vulnerable and low-income patients in a bid to keep costs down.
Official figures showed a fall of two million treatments delivered to patients exempt from NHS charges since 2013-14a fall of $23 \%$ in four years.

At the same time, the number of fines issued had risen more than ten-fold in the last five years, from 33,887 in $2012-13$ to 427,238 in $2017-18$. Of cases appealed, $90 \%$ of appeals were won.

The BDA met with the NAO in early January to urge the watchdog to investigate the issue and has also sought the parliamentary Health and Social Care Select Committee to carry out its own scrutiny.

Charlotte Waite, Chair of the BDA's England Community Dental Services Committee, said: 'This investigation is welcome news. The government's approach to penalty charges has hit hundreds of thousands of vulnerable patients, and encouraged millions more to miss out on care.

'Ministers have told patients not to run the risk when claiming, but offered precious little to make navigating the system any easier. It doesn't matter if you're a patient, a parent or a carer, ticking the wrong box on a form should not come with a $£ 100$ fine.

'Yes, we need a system to protect taxpayer's money, but that does not mean constructing a hostile environment for patients, many of whom have complex needs. An aggressive policy that hurts those who most need the NHS requires real scrutiny.'

\section{References}

1. National Audit Office. Investigation into healthcare penalty charge notices. 2019. Available at https://www.nao.org.uk/work-in-progress/investigation-into-healthcare-penalty-charge-notices/(accessed February 2019)

\section{BOOK REVIEW}

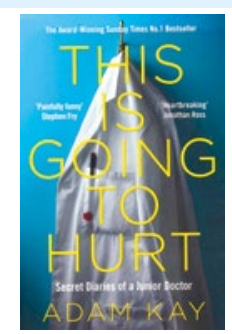

\section{THIS IS GOING TO HURT: SECRET DIARIES OF A JUNIOR DOCTOR}

Adam Kay

2017; Picador

price $f 8.99$ pp. 256

ISBN: 9781509858637

'Everyone working in healthcare should read this book', said a physiotherapist to me recently, and the audience at Adam Kay's sell-out show at the Edinburgh festival seemed to agree, giving the author a standing ovation. Kay, a former trainee in obstetrics and gynaecology, has published a book giving a raw account of his time on the front line of NHS hospitals in London. The author, who has now turned to comedy, left the medical profession aged 30 after a tragic clinical situation in which he was left devastated, unsupported and demoralised.

With Kay's clear aptitude for comedy, the diary entries provide an amusing account of the patients, staff and situations which he encountered during his training. However, there is a clear undertone of the pressures and stress experienced by junior staff and the resultant effect on Kay's relationships, social life and housing situation.

Of most relevance to dentistry is the obvious comparison to colleagues in maxillofacial departments, but any clinical staff will be able to relate to the feelings expressed in the book. It gives a stark reminder of the need to support junior staff and undergraduates in their development and to prevent the early loss of great potential from the profession.

Kay is using the success of his book to raise awareness around the experiences of frontline healthcare staff, speaking widely in the media and at the Royal College of Obstetricians and Gynaecologists conference. With high burnout and suicide rates among dental and medical professionals, it is integral that clinicians are supported, resilience is built and opportunities to debrief are prioritised. Painfully funny, heart-breaking and humbling, Kay's book is one of the most impactful and honest books on healthcare I've read in a long time.

Mhairi Young 